\title{
Spatio-temporal mapping of Madagascar's Malaria Indicator Survey results to assess Plasmodium falciparum endemicity trends between 2011 and 2016
}

Su Yun Kang ${ }^{1}$, Katherine E. Battle ${ }^{1}$, Harry S. Gibson ${ }^{1}$, Arsène Ratsimbasoa ${ }^{2,3}$, Milijaona Randrianarivelojosia 4,5, Stéphanie Ramboarina ${ }^{2,3,6}$, Peter A. Zimmerman ${ }^{6}$, Daniel J. Weiss' ${ }^{1}$, Ewan Cameron ${ }^{1}$, Peter W. Gething ${ }^{1}$ and Rosalind E. Howes ${ }^{1,6^{*}}$

\begin{abstract}
Background: Reliable measures of disease burden over time are necessary to evaluate the impact of interventions and assess sub-national trends in the distribution of infection. Three Malaria Indicator Surveys (MISs) have been conducted in Madagascar since 2011. They provide a valuable resource to assess changes in burden that is complementary to the country's routine case reporting system.

Methods: A Bayesian geostatistical spatio-temporal model was developed in an integrated nested Laplace approximation framework to map the prevalence of Plasmodium falciparum malaria infection among children from 6 to 59 months in age across Madagascar for 2011, 2013 and 2016 based on the MIS datasets. The model was informed by a suite of environmental and socio-demographic covariates known to influence infection prevalence. Spatio-temporal trends were quantified across the country.
\end{abstract}

Results: Despite a relatively small decrease between 2013 and 2016, the prevalence of malaria infection has increased substantially in all areas of Madagascar since 2011. In 2011, almost half (42.3\%) of the country's population lived in areas of very low malaria risk (<1\% parasite prevalence), but by 2016 , this had dropped to only $26.7 \%$ of the population. Meanwhile, the population in high transmission areas (prevalence > 20\%) increased from only 2.2\% in 2011 to $9.2 \%$ in 2016. A comparison of the model-based estimates with the raw MIS results indicates there was an underestimation of the situation in 2016, since the raw figures likely associated with survey timings were delayed until after the peak transmission season.

Conclusions: Malaria remains an important health problem in Madagascar. The monthly and annual prevalence maps developed here provide a way to evaluate the magnitude of change over time, taking into account variability in survey input data. These methods can contribute to monitoring sub-national trends of malaria prevalence in Madagascar as the country aims for geographically progressive elimination.

Keywords: Madagascar, Plasmodium falciparum, Geostatistical model, Map, Malaria Indicator Surveys

* Correspondence: rosalind.howes@bdi.ox.ac.uk

${ }^{1}$ Malaria Atlas Project, Oxford Big Data Institute, Nuffield Department of

Medicine, University of Oxford, Oxford, UK

${ }^{6}$ Center for Global Health and Diseases, Case Western Reserve University,

Cleveland, $\mathrm{OH}$, USA

Full list of author information is available at the end of the article

(c) The Author(s). 2018 Open Access This article is distributed under the terms of the Creative Commons Attribution 4.0 International License (http://creativecommons.org/licenses/by/4.0/), which permits unrestricted use, distribution, and reproduction in any medium, provided you give appropriate credit to the original author(s) and the source, provide a link to the Creative Commons license, and indicate if changes were made. The Creative Commons Public Domain Dedication waiver (http://creativecommons.org/publicdomain/zero/1.0/) applies to the data made available in this article, unless otherwise stated. 


\section{Background}

Malaria remains an important public health problem in Madagascar despite concerted efforts over decades to control transmission. At times, these interventions, which have been primarily focussed on targeted vector control, have successfully reduced transmission to very low levels [1-3]. The island's malaria epidemiology is highly varied, reflecting a diverse ecological environment, with differing seasonal trends across the country [4], which can be further affected by unpredictable cyclonic activity that impedes malaria control efforts. Epidemics have punctuated the history of malaria in Madagascar [5]. They are closely associated with the spread of rice production [6] and remain an important component of the disease epidemiology [7]. Domestic political support and international investment following the turn of the century led to impressive reductions in transmission up to 2008, but were followed by a period of stagnation and subsequent reversal of progress in the aftermath of political instability in 2009 and funding disbursement delays [4].

The National Malaria Control Programme (NMCP) of Madagascar has recently entered a new phase, marked by the inauguration of the 2018-2022 National Strategic Plan for Malaria, which includes ambitious targets for progress towards elimination during this period [8]. Central to optimising the intervention policy strategy for the coming 5 years is a thorough understanding of the current epidemiological situation across the country and of the impact of investments in recent years. While routinely reported clinical case data can provide insight into general tendencies in the burden of malaria in Madagascar [4], important uncertainties associated with this stream of data present difficulties with robustly quantifying spatiotemporal trends. Madagascar has benefited from three Malaria Indicator Surveys (MIS 2011, 2013 and 2016), which provide standardised and rigorous measures of malaria endemicity at high spatial resolution from representative population samples from across the island [9-11].

A recent overview of Madagascar's routine malaria case data from 2010 to 2015 described the trends in reported case data across eight ecozones, which are programmatically relevant clusters of spatially contiguous districts that share similar malaria epidemiological characteristics [4] (Fig. 1). This sub-national perspective offered insight into important variation in malaria burden across the island's different environmental zones. The overview identified an increase in numbers of confirmed malaria cases. This is explained in part by increased access to rapid diagnostic tests, but also by a growing malaria burden, which is indicated by a significant rate of increase in the diagnostic positivity rate between $2010(33 \%)$ and $2015(50 \%)(p<0.0001)$. The routine reported case data, therefore, indicate there was an increasing malaria burden from 2010 to 2015 .

The quality of data reporting through a country's routine health information system, however, can vary, potentially impacting the reliability of the nationally aggregated health statistics as malariometric indicators, especially in a resource-limited setting such as Madagascar, which has a fragile health and communications infrastructure [12]. At

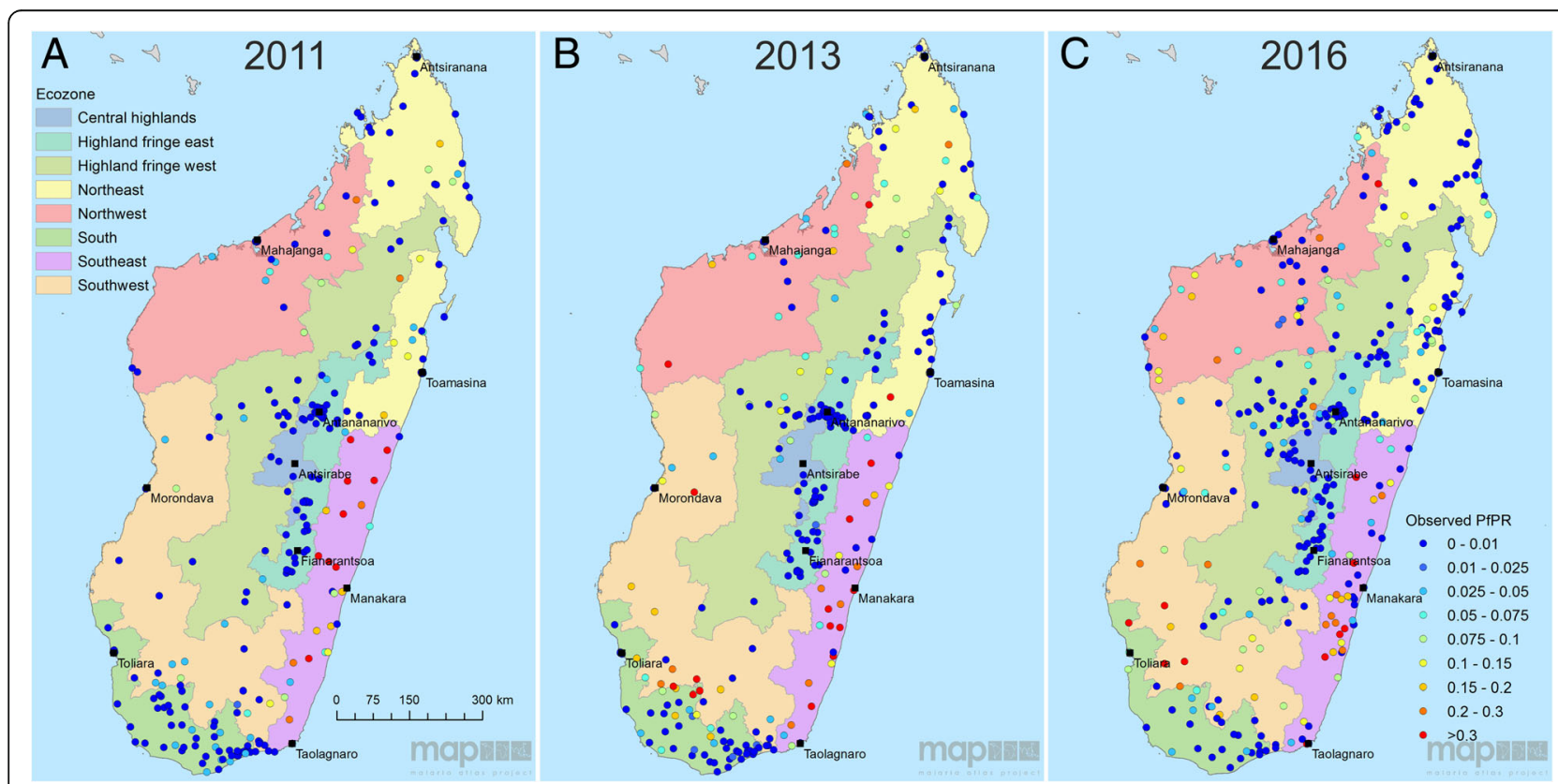

Fig. 1 Malaria Indicator Survey screening sites for (a) 2011, (b) 2013 and (c) 2016. The coloured regions represent the country's eight malaria ecozones [4] 
every step of the data reporting chain, cases are lost from the system [13], for example from patients not interacting with public health facilities during malaria episodes [14], rapid diagnostic test stock-outs resulting in unconfirmed infections, or accessibility difficulties for health workers submitting monthly activity reports to the centralised database etc. [4]. Reported numbers can, therefore, be strongly influenced by factors external to the true underlying epidemiology.

MIS datasets provide a complementary perspective on recent trends in malaria endemicity, free from the intrinsic limitations of reported case data. Their strength lies in their standardised methodology applied repeatedly over multiple years across nationally representative sites. This present study uses the MIS data to map the prevalence of infection by Plasmodium falciparum in those under 5 years old (6 to 59 months in age: $P f \mathrm{PR}_{6-59 \mathrm{mo}}$ ) to obtain a deeper insight into epidemiological trends than that available from the published MIS overview analyses, which reported aggregated national prevalence rates of $6.2 \%$ for 2011 [9], 9.1\% for 2013 [10] and $7.0 \%$ for 2016 [11]. This study aims to generate spatially continuous prevalence maps that account for disparities in sample collection dates between the different MIS years. This variation in the time window is not otherwise accounted for in the published MIS analyses [9-11]. The maps provide a benchmark of transmission intensity, free from the nuances of the datasets of routinely reported case data. These can support strategic resource allocation and allow progress towards the current strategic plan goals to be monitored.

\section{Methods}

\section{Study data}

Parasite prevalence data for this study came from MIS activities conducted across Madagascar in 2011, 2013 and 2016. Alongside many other indicators, an MIS includes measurements of the prevalence of $P$. falciparum infection among children 6 to 59 months old $\left(P f \mathrm{PR}_{6-59 \mathrm{mo}}\right)$, based on a standardised protocol with a stratified sampling strategy across the island that is designed to capture a nationally representative assessment of prevalence. Data are freely available from the Demographic and Health Surveys (DHS) online repository. Across the three MIS years, a total of 898 spatially unique geo-positioned datapoints were available, which reported prevalence of infection among 19,986 children. The initial survey in 2011 included 266 sites (29.6\% overall; 6827 individuals), screened from March to May. In 2013, 274 sites (30.5\%; 6232 individuals) were screened between April and June. Finally, in 2016, 358 sites (39.9\%; 6927 individuals) were screened from April to July. The diagnostic outcomes used here were from microscopy, read by the Institut Pasteur de Madagascar and NMCP parasitology teams. Survey locations are plotted by year in Fig. 1 and by month in Additional file 1: Figure S1. The maps reveal a west to east longitudinal gradient in the cluster sampling in both 2013 and 2016, with the high endemicity east coast sampled later than western and central populations. This sampling bias, with the east coast sampled later in the transmission season, reinforced the need to account for this in the model structure. Full details of the MIS protocols are available in the original published reports [9-11].

Environmental and socio-demographic variables known to interact with and influence $P$. falciparum prevalence [15] were assembled as 30 arcsecond spatial grids (Table 1). Among the suite of covariates, eight were temporally static covariates. The socio-demographic variables included stable night-time lights in 2010 [16], which indicated the presence of cities or towns [17], and accessibility to cities, which quantified travel time to cities larger than 50,000 people [18]. Static environmental variables included elevation as measured from the Shuttle Radar Topography Mission (SRTM) [19], slope, which was calculated from that elevation in ArcGIS 10.5.1 [20], and a measure of distance to water, which indicates the Euclidean distance to permanent and semi-permanent water based on the presence of lakes, wetlands, rivers and streams, and accounts for slope and precipitation [21,22]. Also included were indices of aridity [23], potential evapotranspiration [23] and topographic wetness (which was calculated from the SRTM elevation surface).

Temporally dynamic covariates are those for which data were available at monthly intervals, or, for population density, annual intervals [24]. Precipitation data were obtained from the Climate Hazards Group Infrared Precipitation with Station data (CHIRPS) [25]. A P. falciparum-specific covariate developed by the Malaria Atlas Project that measures the suitability of air temperature for malaria transmission $[26,27]$ was included after it was extended to the full study period. The remaining dynamic variables were obtained from Moderate Resolution Imaging Spectroradiometer (MODIS) satellite data [28]. Note that these data were first gap-filled [29] to remove missing values, such as due to cloud cover, before being aggregated to monthly measurements. Three products of temperature data were derived from land surface temperature (LST), including (i) daytime LST, (ii) night-time LST and (iii) the diurnal difference of daytime to night-time LST [30]. MODIS reflectance data were used for measurements of vegetation and moisture: enhanced vegetation index (EVI) [31], tasselled cap brightness (TCB) and tasselled cap wetness (TCW) [32].

The values of the covariate data at the MIS screening locations were extracted for all points. Temporally dynamic covariates were matched to the same month as the survey, as well as 1, 2 and 3 months prior to the survey (lags). 
Table 1 List of environmental and socio-demographic covariates

\begin{tabular}{|c|c|c|c|c|c|}
\hline Covariate & Description & Dynamic & $\begin{array}{l}\text { Round } 1 \\
\text { selection }\end{array}$ & $\begin{array}{l}\text { Round } 2 \\
\text { selection }\end{array}$ & Source \\
\hline Accessibility & Distance to cities with population $>50,000$ & Static & Yes & Yes & Nelson [18] \\
\hline $\mathrm{Al}$ & Aridity index & Static & Yes & Yes & World Clim [23] \\
\hline DistToWater & $\begin{array}{l}\text { GIS-derived surface that measures distance } \\
\text { to permanent and semi-permanent water } \\
\text { based on presence of lakes, wetlands, rivers } \\
\text { and streams, and accounting for slope and } \\
\text { precipitation }\end{array}$ & Static & Yes & Yes & $\begin{array}{l}\text { MAP (from WWF surfaces } \\
{[21,22] \text { ) }}\end{array}$ \\
\hline Elevation & $\begin{array}{l}\text { Elevation as measured by the Shuttle Radar } \\
\text { Topography Mission (SRTM) }\end{array}$ & Static & Yes & Yes & SRTM derivative [19] \\
\hline PET & Potential evapotranspiration & Static & Yes & Yes & Trabucco \& Zomer [23] \\
\hline Slope & $\begin{array}{l}\text { GIS-derived surface calculated from SRTM } \\
\text { elevation surface }\end{array}$ & Static & Yes & Yes & MAP (from SRTM [19]) \\
\hline Stable_Lights_2010 & $\begin{array}{l}\text { Index that measures the presence of lights } \\
\text { from towns, cities and other sites with } \\
\text { persistent lighting }\end{array}$ & Static & Yes & Yes & NOAA [16] \\
\hline TWI & Topographic wetness index & Static & Yes & Yes & MAP (from SRTM [19]) \\
\hline Population size & Estimated population per $1 \mathrm{~km} \times 1 \mathrm{~km}$ pixel & Annual & Yes & & Linard et al. [24] \\
\hline $\mathrm{EVI}$ & Enhanced vegetation index & Monthly & $\operatorname{Lag} 0,3$ & Lag 3 & MODIS derivative [31] \\
\hline LST_day & Daytime land surface temperature & Monthly & & & MODIS derivative [30] \\
\hline LST_delta & $\begin{array}{l}\text { Diurnal difference in land surface } \\
\text { temperature }\end{array}$ & Monthly & $\operatorname{Lag} 0,1,2,3$ & $\operatorname{Lag} 0,1,2,3$ & MODIS derivative [30] \\
\hline LST_night & Night-time land surface temperature & Monthly & & & MODIS derivative [30] \\
\hline TCB & $\begin{array}{l}\text { Tasselled cap brightness; measure of land } \\
\text { reflectance }\end{array}$ & Monthly & $\operatorname{Lag} 0,2$ & $\operatorname{Lag} 2$ & MODIS derivative [32] \\
\hline TCW & Tasselled cap wetness & Monthly & Lag 3 & Lag 3 & MODIS derivative [32] \\
\hline TSI & Temperature suitability index & Monthly & $\operatorname{Lag} 0,1,2,3$ & & MAP [26] \\
\hline CHIRPS & $\begin{array}{l}\text { Climate Hazards Group Infrared Precipitation } \\
\text { with Station Data }\end{array}$ & Monthly & $\operatorname{Lag} 0,1,2,3$ & $\operatorname{Lag} 0,1,3$ & CHIRPS [25] \\
\hline
\end{tabular}

CHIRPS Climate Hazards Group Infrared Precipitation with Station Data, GIS geographic information system, MAP Malaria Atlas Project, MODIS Moderate Resolution Imaging Spectroradiometer, NOAA National Oceanic and Atmospheric Administration, SRTM Shuttle Radar Topography Mission, WWF World Wildlife Fund

\section{Bayesian spatio-temporal model}

Parasite prevalence data $\left(P f \mathrm{PR}_{6-59 \mathrm{mo}}\right)$ were modelled via a Bayesian binomial logistic regression model with spatiotemporal random effects accounting for a spatial latent process varying with time. An integrated nested Laplace approximation [33] was adopted for model inference and prediction. The spatio-temporal random effects were modelled using stochastic partial differential equations [34], which represent a Matérn spatio-temporal Gaussian field as a Gaussian Markov random field via triangulation.

Let $Y_{l t}, n_{l t}$ and $p_{l t}$ be the number of infected individuals, the number of individuals screened and the prevalence of infection by $P$. falciparum at geocoded location $l(l=1, \ldots, N)$ for time $t(t=1, \ldots, T) . Y_{l t}$ is assumed to follow a binomial distribution:

$$
Y_{l t} \sim \operatorname{Bin}\left(p_{l t}, n_{l t}\right)
$$

The prevalence of infection, $p_{l t}$, is modelled via a linear regression on the logit scale:

$$
\operatorname{logit}\left(p_{l t}\right)=X_{l t}^{T} \boldsymbol{\beta}+f(\text { Year })+\phi_{l t} .
$$

The matrix $X$ includes an intercept and a list of environmental and socio-demographic covariates known to affect prevalence. $\beta$ is the vector of regression coefficient, $f$ (Year) is a temporal random effect accounting for differences in years in the prevalence data and $\phi_{l t}$ is the spatiotemporally structured random effects. The temporal random effect, $f$ (Year), is assigned a first-order autoregressive prior distribution (AR1). Monthly variations in the data are captured via the spatio-temporal process $\phi_{l t}$, which changes in time with an AR1 process modelled at two semi-annual scales, as follows:

$$
\begin{array}{ll}
\phi_{l, t}=\varepsilon_{l 1}, & \text { if } t=1, \\
\phi_{l, t}=a \phi_{l, t-1}+\varepsilon_{l, t}, & \text { if } t=2,
\end{array}
$$

where $a(|a|<1)$ is a temporal autoregressive coefficient and $\phi_{l, t}$ is the vector of the spatio-temporally structured effect, which follows a multivariate normal distribution with zero mean and a spatio-temporal covariance function 
of the Matérn family. See [34] for more details of the specification of the spatio-temporal random field. Since the prevalence data were only available for certain months each year, the AR1 process (time effect) of $\phi_{l, t}$ is modelled at two half-year intervals to ensure continuity: December to May and June to November.

As part of the variable selection procedure, collinearity among the environmental covariates was examined by calculating variance inflation factors (VIFs) prior to fitting the statistical model to the prevalence data. A stepwise selection of covariates using VIFs was undertaken to make sure all VIF values are below a desired threshold (VIF $<10$ in this case). Put simply, using the full set of covariates, a VIF for each variable was calculated. The variable with the single highest value was removed and all VIF values with the new set of variables were recalculated. Then, the variable with the next highest value was removed, and so on, until all VIF values were below the threshold of 10 . This resulted in a set of 26 covariates being considered for model fitting (Table 1, Round 1 selection). Subsequently, variable selection was performed using bidirectional elimination by running stepwise regressions on all model combinations using the 26 chosen covariates. The best-fitting (final) model had the smallest deviance information criterion value and included 18 covariates (Table 1, Round 2 selection).

Using the final model, the prevalence of infection by $P$. falciparum (PfPR ${ }_{6-59 m o}$ ) was predicted over a 30 arcsecond spatial grid of 1,602,342 pixels (approximately $1 \mathrm{~km} \times 1 \mathrm{~km}$ spatial resolution) for each month of 2011, 2013 and 2016. The final covariates were available at monthly intervals and this allowed us to make monthly predictions of prevalence. The resulting predictions included the monthly mean prevalence and the monthly interquartile range (IQR) of prevalence as a measure of the associated prediction uncertainty. The annual mean prevalence $\left(P f \mathrm{PR}_{6-59 \mathrm{mo}}\right)$ and mean IQR were obtained by averaging across the 12 monthly predictions.

This Bayesian model-based geostatistical approach allows the smoothing of extreme rates due to small sample sizes by borrowing strength across neighbouring pixels to improve local estimates. Essentially, the approach assumes a positive spatial correlation between observations, borrows more information from neighbouring pixels than from pixels far away (in both space and time), and smooths local rates toward local, neighbouring values. The resulting smoothed prevalence estimates are robust and reliable while circumventing the issue of sparse data [35]. The inherently hierarchical structure of the current modelling framework permits the model-based estimation of covariate effects, the prediction of missing data and the estimation of spatio-temporal covariance structures [36]. Model predictions are presented at the pixel level and also summarised by ecozone [4].
A range of model validation analyses were used to assess the model's goodness of fit and predictive accuracy, including the Pearson correlation of observed and predicted data, and validation runs with incremental holdout validation data subsets.

\section{Results}

\section{The model framework}

The Bayesian spatio-temporal model was developed in an integrated nested Laplace approximation framework to map the prevalence of $P$. falciparum malaria infection among children aged 6 to 59 months in age (PfPR $6-59$ mo $)$ across Madagascar for 2011, 2013 and 2016. Validation of the final model gave Pearson correlation coefficients of $0.96,0.94$ and 0.83 for each prediction year, respectively, between month-specific predicted and observed prevalence (Additional file 2: Figure S2), justifying a good fit of the Bayesian spatio-temporal model to the observed prevalence data. To assess the predictive power of the specified model, prevalence data were split into two sets: a training set $\left(D_{t}\right)$ and a validation set $\left(D_{v}\right)$ [37]. After being trained on $D_{t}$, the model accuracy was determined by its ability to predict $D_{v}$ as well as the entire prevalence dataset. A percentage of $D_{v}$ was chosen to be a random sample of $10 \%, 20 \%, 30 \%$ and $40 \%$ of the overall dataset. Each validation was repeated 100 times and the model accuracy was averaged across the 100 fitted models. The box plots of cross-validated correlations appeared satisfactory (Additional file 3: Figure S3a). The cross-validated $R^{2}$ had a mean of 0.78 and a range of $(0.70,0.83)$ for $10 \% D_{v}$; a mean of 0.72 and a range of $(0.62,0.79)$ for $20 \% D_{v}$; a mean of 0.65 and a range of $(0.55,0.74)$ for $30 \% D_{v}$; and a mean of 0.58 and a range of $(0.45,0.68)$ for $40 \% D_{v}$ (Additional file 3 : Figure S3b). The model was deemed accurate in its ability to predict a wide range of validation sets (Additional file 4: Figure S4).

\section{Covariates}

The combination of covariates that together best explained the spatio-temporal variation in the PfPR datapoints were selected for inclusion in the spatio-temporal model and are listed in Tables 1 (Round 2 selection) and 2. Out of the 18 predictors which informed the statistical model, eight predictors were significant based on their 95\% Bayesian credible intervals, namely LST_delta_2, TWI, PET, CHIRPS_1, Accessibility, Elevation, CHIRPS_0 and TCW_3. Of these eight predictors, LST_delta_2 (diurnal variation in land surface temperature 2 months prior to the prediction month) had a positive effect on the odds of risk with odds ratio $\mathrm{OR}=1.1987$. The odds of $P$. falciparum infection were negatively associated with TCW_3 (an index of surface wetness 3 months prior to the prediction month) with $\mathrm{OR}=0.0025$. The remaining six covariates had OR slightly 
Table 2 Regression coefficients and odds ratios of the predictors selected by the final model and their associated 95\% Bayesian credible intervals $(\mathrm{Cl})$

\begin{tabular}{lllll}
\hline Covariate & Regression coefficient & $95 \%$ Cl of regression coefficient & Odds ratio & $95 \%$ Cl of odds ratio \\
\hline EVI_3 & 1.5872 & $(-0.3861,3.5926)$ & 4.8913 & $(0.6799,36.3362)$ \\
LST_delta_2 & 0.1812 & $(0.1098,0.2527)^{*}$ & 1.1987 & $(1.1161,1.2876)^{*}$ \\
TWI & 0.0535 & $(0.0048,0.1017)^{*}$ & 1.0550 & $(1.0048,1.1071)^{*}$ \\
PET & 0.0028 & $(0.0009,0.0048)^{*}$ & 1.0028 & $(1.0009,1.0048)^{*}$ \\
CHIRPS_1 & 0.0023 & $(0.0010,0.0037)^{*}$ & 1.0023 & $(1.0010,1.0037)^{*}$ \\
Accessibility & 0.0020 & $(0.0009,0.0031)^{*}$ & 1.0020 & $(1.0009,1.0031)^{*}$ \\
CHIRPS_3 & 0.0004 & $(-0.0010,0.0018)$ & 1.0004 & $(0.9990,1.0018)$ \\
Al & 0.0001 & $(0.0000,0.0002)$ & 1.0001 & $(1.0000,1.0002)$ \\
DistToWater & 0.0000 & $(0.0000,0.0001)$ & 1.0000 & $(1.0000,1.0001)$ \\
Slope & 0.0000 & $(0.0000,0.0000)$ & 1.0000 & $(1.0000,1.0000)$ \\
Elevation & -0.0015 & $(-0.0022,-0.0009)^{*}$ & 0.9985 & $(0.9978,0.9991)^{*}$ \\
CHIRPS_0 & -0.0020 & $(-0.0036,-0.0004)^{*}$ & 0.9980 & $(0.9964,0.9996)^{*}$ \\
LST_delta_1 & -0.0111 & $(-0.0944,0.0721)$ & 0.9889 & $(0.9099,1.0748)$ \\
Stable_Lights_2010 & -0.0274 & $(-0.0801,0.0218)$ & 0.9730 & $(0.9231,1.0221)$ \\
LST_delta_3 & -0.0532 & $(-0.1173,0.0106)$ & $(-0.1360,0.0281)$ & $(0.8894,1.0106)$ \\
LST_delta_0 & -0.0540 & $(-5.2983,1.8037)$ & $(-10.7712,-1.2680)^{*}$ & $(0.8729,1.0285)$ \\
TCB_2 & -1.7339 & $(-15.6992,-7.5190)$ & 0.9475 & $(0.0050,6.0672)$ \\
TCW_3 & -5.9884 & & 0.1765 & $(0.0000,0.2813)^{*}$ \\
Intercept & -11.5150 & 0.0025 & $(0.0000,0.0005)$ \\
\hline Clisedis & 0.0000 &
\end{tabular}

$\mathrm{Cl}$ credible interval

*Significant based on 95\% Bayesian credible interval

above or below 1, indicating that they did not have a large influence on the odds of risk. Note that the final model also included several predictors with OR being roughly one, namely aridity index, distance to water and slope, which suggests that they did not affect the odds of $P$. falciparum infection. However, the model selection procedure that optimised the deviance information criterion value justified the need to retain these predictors in the model.

Monthly variation in the key predictors is summarised at the national level in Fig. 2 and by the previously defined ecozones [4] in Additional file 5: Figure S5. These box plots include the temporally dynamic environmental predictors that informed the statistical model over different time lags. For example, EVI with a 3month lag indicates that the malaria prevalence prediction for January 2011 was informed by the EVI level in October 2010. LST_delta, or the diurnal variation in land surface temperature, was influential across the whole time window up to 3 months prior to the prediction months. Predictions for January 2011, for example, were influenced by the difference in daytime and nighttime temperatures (LST_delta) in October, November and December 2010, as well as January 2011. Seasonal variation in the different dynamic predictors differed in amplitude, with the most extreme being the CHIRPS dataset (a precipitation indicator), which dropped to very low between May and September. In contrast, the tasselled cap wetness (a remotely sensed transformed index of land surface water availability) remained relatively constant over time, with no significant monthly variation when summarised to the national level. At the higherresolution ecozone level, ecological predictors show more extreme temporal variation, emphasising the country's environmental diversity. Put together, these constellations of monthly dynamic explanatory variables combined with the static predictors explained the spatio-temporal variation in the input data and informed extrapolation to locations and time points that were not represented in the MIS input datasets.

\section{Spatio-temporal trends in malaria endemicity}

This paper's primary objective was to assess changes in the prevalence of $P$. falciparum malaria infection among those under 5 years old $\left(P f \mathrm{PR}_{6-59 \mathrm{mo}}\right)$ in Madagascar between the three surveyed years of 2011, 2013 and 2016. The published MIS reports gave national prevalence estimates for the 6-59 month age group of $6.2 \%$ [9], 9.1\% [10] and 7.0\% [11], respectively. The geostatistical model developed here generated 36 monthly prediction maps of endemicity (Additional file 5: Figure S5 and Additional file 6: Figure S6), which are summarised into three annual mean predictions (Fig. $3 \mathrm{a}-\mathrm{C}$ ), with ecozone-level box plot 

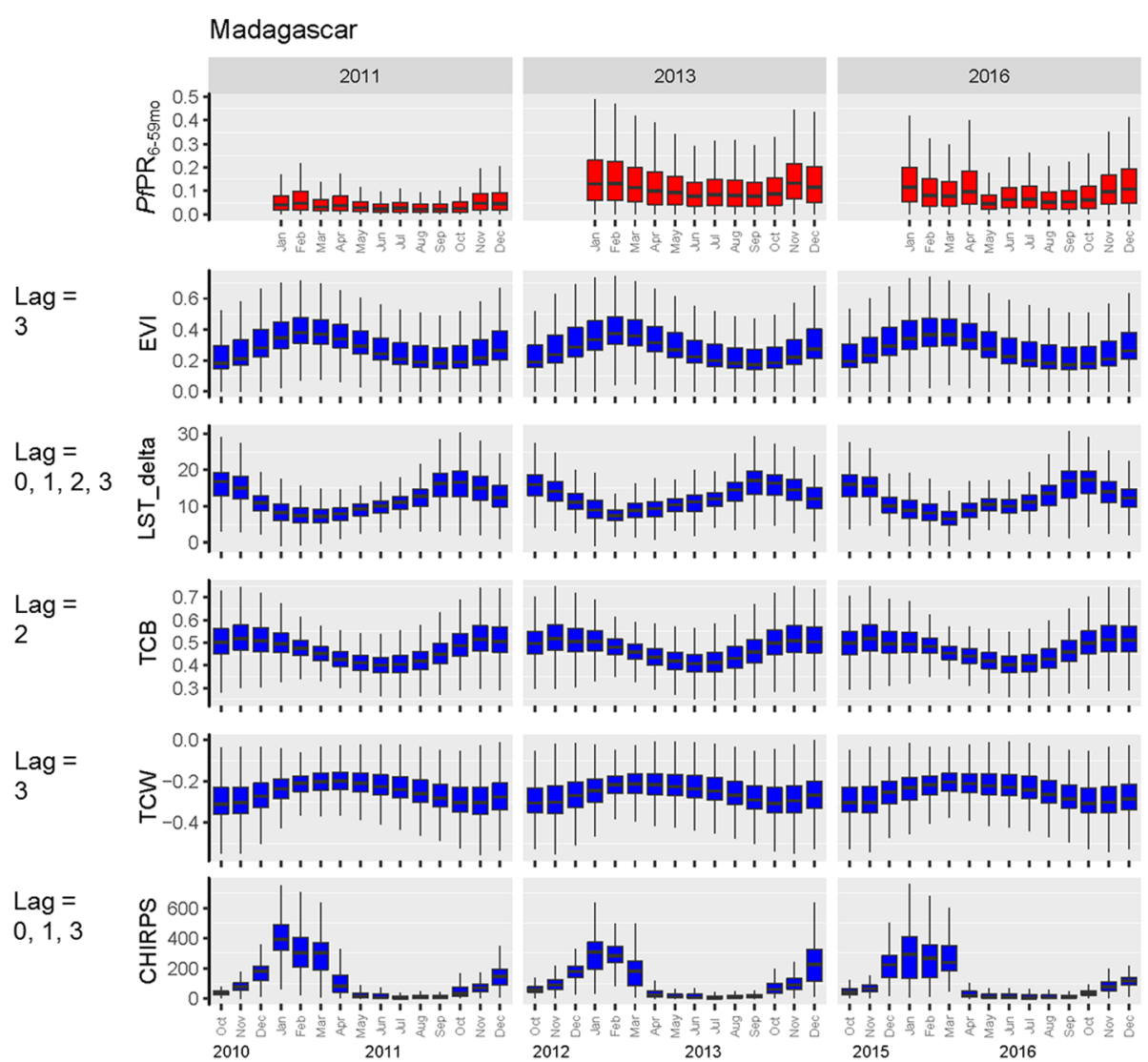

Fig. 2 National-level mean monthly PfPR6-59mo predictions, plotted alongside temporally variable predictor values. The box plot rectangles indicate the first to third quartiles (interquartile range), with the median shown as the dark line inside the box. Vertical lines correspond to the minimum and maximum values. Specified lags indicate the time points that were selected by the model as explanatory variables of PfPR $6-59 \mathrm{mo}$. A time lag of 0 indicates that the covariate values in the concurrent month were predictive of PfPR $6-59 \mathrm{mo}$, while a time lag of 3 indicates that the covariate value 3 months prior to the PAPR $6-59 \mathrm{mo}$ prediction was predictive of $P A P R_{6-59 m o}$

summaries of trends across the country's eight ecozones given in Fig. 4. Together, these model outputs allow spatio-temporal trends to be examined at different spatial and temporal scales: national, ecozone or pixel level, and monthly or annually. Model uncertainty is mapped alongside the mean $P f \mathrm{PR}_{6-59 \mathrm{mo}}$ prediction surfaces as the IQR of the model posterior distribution (Fig. $3 \mathrm{~d}-\mathrm{f}$ and Additional file 6: Figure S6b, d, f), quantifying confidence in the model predictions. Coefficients of variation (standard deviation/mean) for each annual prediction are plotted in Additional file 7: Figure S7 to reflect the relative variability of the predictions. Together, these uncertainty maps show that while the absolute uncertainty (represented by the IQR) is lower in the central highlands where prevalence is lowest, when adjusted to the mean prediction values, confidence in the prediction is strongest in coastal areas where prevalence is higher.

Malaria endemicity remains spatially heterogeneous across Madagascar (Figs. 3 and 4), with the central highlands consistently having the lowest endemicity across the 3 years evaluated $\left(<1 \%\right.$ mean annual $\left.P f \mathrm{PR}_{6-59 \mathrm{mo}}\right)$. To the east, a sharp transition towards the coast culminates in high prevalence regions, with pockets along the south-east coast with $>30 \%$ mean annual prevalence, expanding in extent from 2011 into subsequent years. High prevalence in this ecozone is not homogeneous however, being interspersed with pockets of lower endemicity $(<7.5 \%$ PfPR $6-59 \mathrm{mo})$. The island's west coast is similarly high in prevalence, almost universally with $P_{f P R_{6-59 m o}}>10 \%$ and with areas $>30 \%$ mean annual ${ }^{P f P R}{ }_{6-59 m o}$ prevalence. The northern and southern tips have lower prevalence, typically under 5\% endemicity. Confidence in the model predictions was variable across the country and between years. The low-prevalence data-rich highlands were modelled with greater confidence than the more heterogeneous coastal regions, where survey data indicated spatially variable rates of infection (Figs. 1 and $3 \mathrm{~d}-\mathrm{f}$ ). The highest model uncertainty in all 3 years was in the north-eastern region of Sava, an area previously characterised as a malaria parasite transmission hotspot [38]. As seen across the whole 


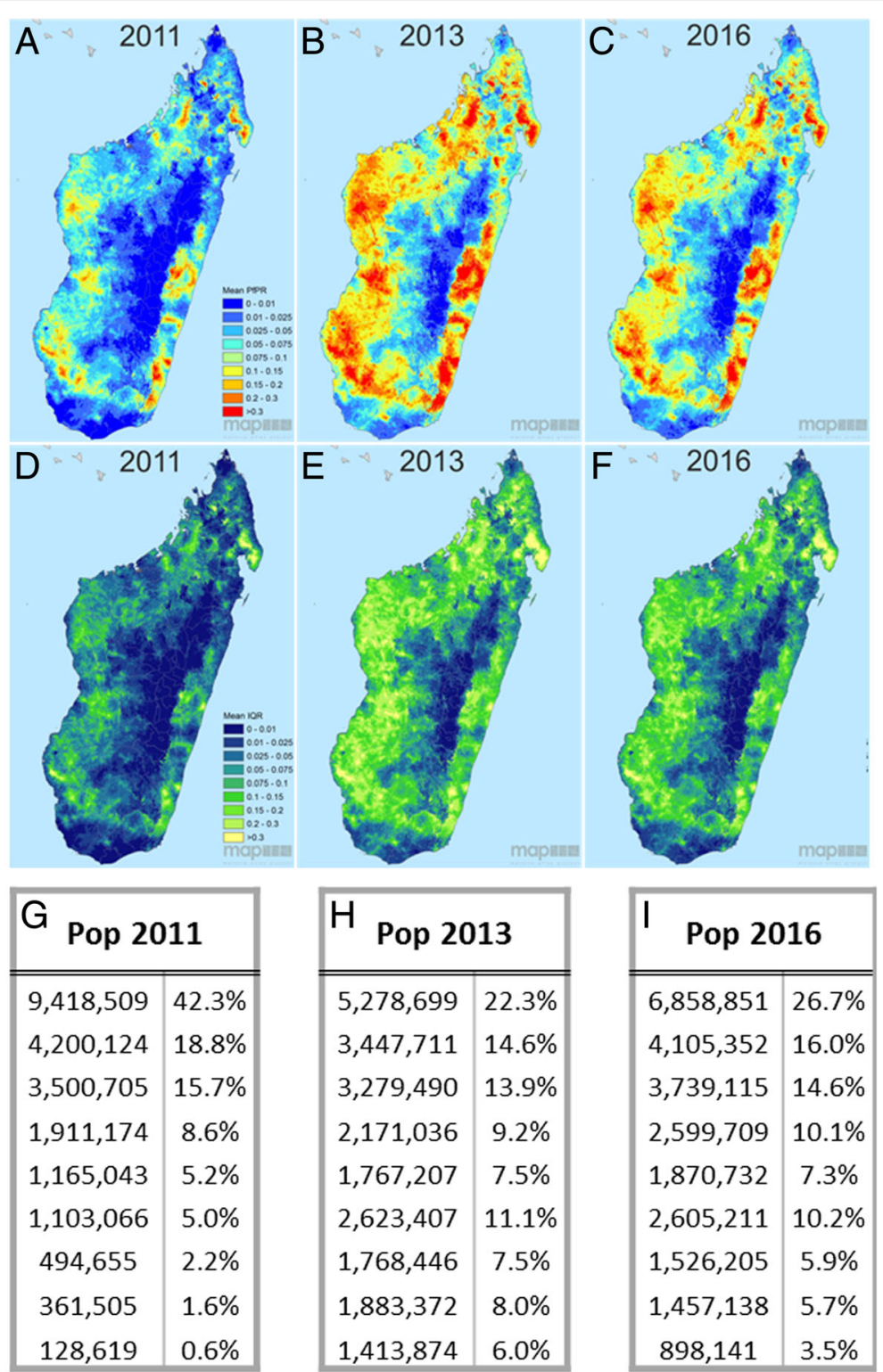

Fig. 3 Predicted annual mean PfPR among children 6 to 59 months in age for 2011 (a), 2013 (b) and 2016 (c). d-f The corresponding map uncertainty (quantified as the prediction interquartile range). Values are mapped at $1 \times 1 \mathrm{~km}$ pixel resolution. $\mathbf{g}$-i National population breakdown by endemicity class, using population values based on WorldPop's Whole Continent UN-adjusted Population Count datasets for Africa for 2010, 2015 and 2020 . Estimates for 2011, 2013 and 2016 were created by linear interpolation of the bookending quinquennial rasters

country after 2011, the higher observed prevalence was associated with a larger IQR, reflecting the wider range of potential prevalence values.

At the national level, the three mean annual maps were all significantly different from one another (Wilcoxon rank sum test, $\left.p<2.2 \times 10^{-16}\right)$. PfPR 6 -59mo more than doubled between 2011 and 2016 (127\% increase across the mean annual maps; Fig. 5a and c), despite a 23\% decrease within that window between 2013 and 2016 (Fig. 5b and d). Changes in endemicity were spatially variable across the period examined. The magnitude of change across the country between 2011 and 2016 was highly heterogeneous, with a standard deviation of $34.0 \%$ around the $127 \%$ mean increase. All ecozones experienced at least a doubling in prevalence of $P f \mathrm{PR}_{6-59 \mathrm{mo}}$ between 2011 and 2016, with the smallest proportional change being in the southeast (100.4\%; Fig. 4 and Additional file 5: Figure S5d) and the highest up to $157.4 \%$ in the central highlands, where prevalence nevertheless remained the lowest (Fig. 4 and Additional file 5: Figure S5h). The south ecozone also saw an important increase of $142.5 \%$ over the 6-year period (Fig. 4 and Additional file 5: Figure S5g). The $23 \%$ mean fall in prevalence from 2013 to 2016 was fairly consistent across the whole country 


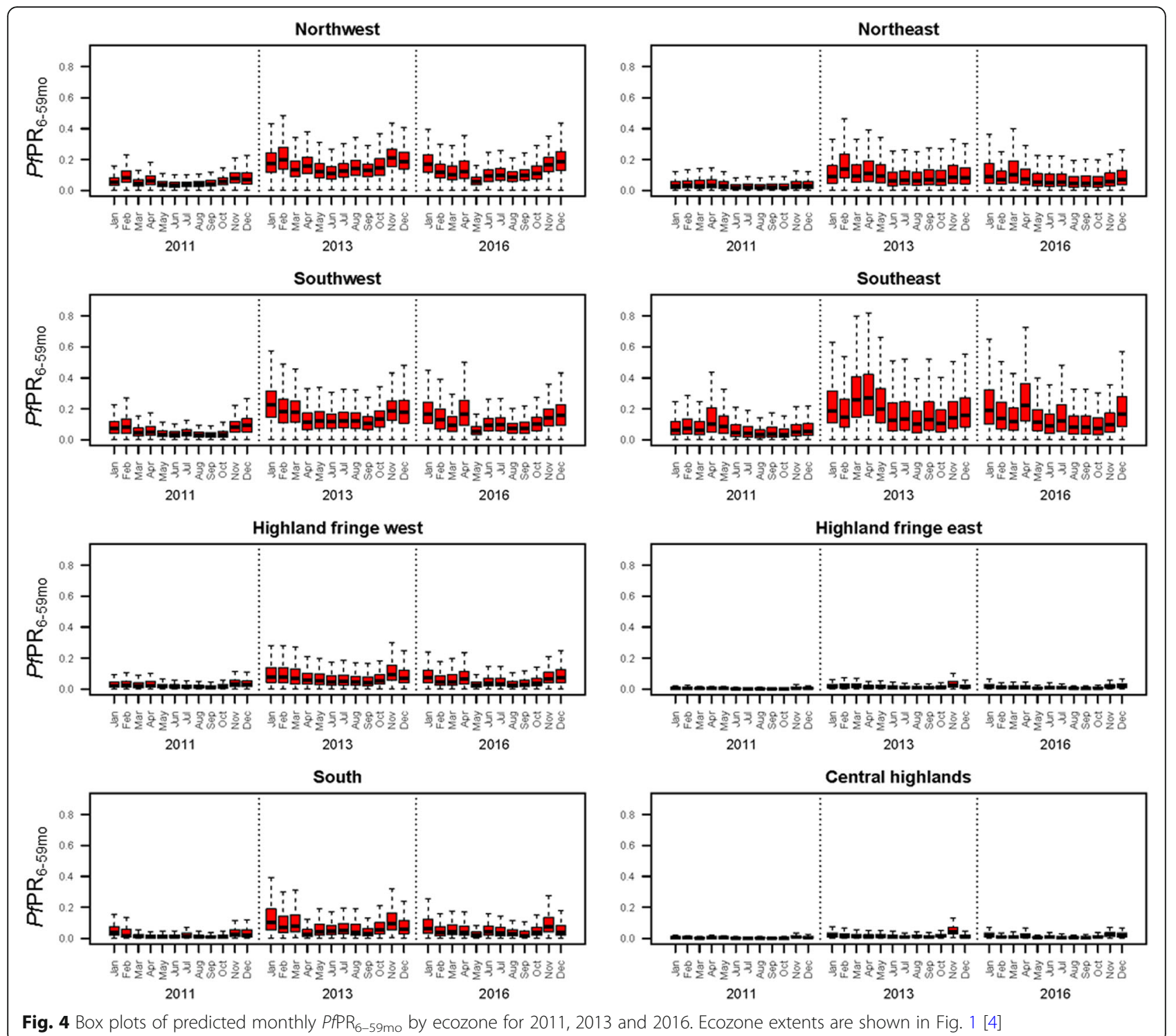

(standard deviation 7.4\%), and at the ecozone level, ranged from a $20.7 \%$ decrease in the central highlands to a $27.4 \%$ decrease in the eastern highland fringe zone. At the pixel level, $96 \%$ of pixels experienced a decrease of $10 \%$ to $50 \%$ between 2013 and 2016. In contrast, 27\% of pixels increased between $0 \%$ and $100 \%$, and $71 \%$ more than doubled in prevalence over the full study period from 2011 to 2016 .

\section{Trends in population exposure}

Converting the geographic maps into population exposure rates offers insight into the relative intensity of infection prevalence across the population. The density of which is highly variable across the island [4]. Fig. $3 g-i$ summarises the population numbers resident in each of the different endemicity categories. These show that the majority of the Malagasy population lives in the lowest endemicity areas, with almost half (42\%) of the population in very low endemicity areas $(<1 \%$ mean annual $\left.P f \mathrm{PR}_{6-59 \mathrm{mo}}\right)$ and less than $10 \%$ in areas where $P f \mathrm{PR}_{6-59 \mathrm{mo}}$ was $>10 \%$ in 2011 . The highest endemicity year, 2013, was predicted to have $32.5 \%$ of the population in areas where endemicity was $>10 \%$, a threefold increase from 2011. By 2016, this had dropped to 25.3\% of the population being in areas of $>10 \%$ prevalence, with a corresponding increase in the proportion living in very low $(<1 \%)$ prevalence areas to $26.7 \%$. Finally, the proportion of the population with infection prevalence greater than 20\% rose from 2.2\% in 2011 (an estimated 0.5 million individuals) to $14.0 \%$ in 2013 (3.3 million individuals) and 9.2\% (2.4 million individuals) in 2016. Trends in endemicity across the population, therefore, reflect the overall tendencies in the geographic maps, with sharp increases in infection prevalence in the 

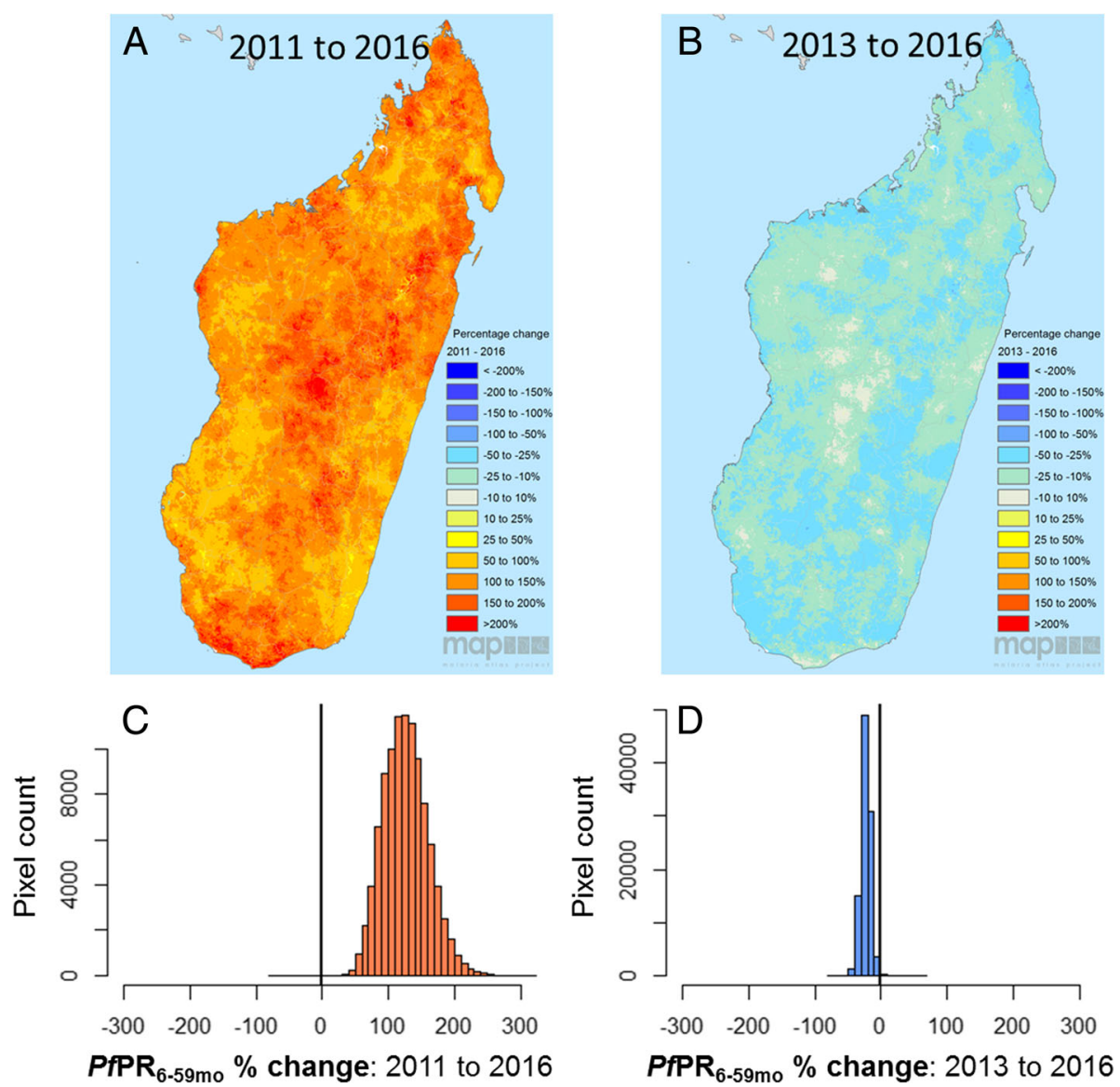

Fig. 5 Percentage changes in predicted PfPR among children 6 to 59 months old across the three MIS time points: a from 2011 to 2016 and $\mathbf{b}$ from 2013 to 2016. Histograms of pixel-level change c from 2011 to 2016 and d from 2013 to 2016. Positive \% change indicates an increase in prevalence, while negative $\%$ change is a decrease

low endemicity areas where most of the population lives, and notable increases in the population exposed to the highest end of the endemicity spectrum. A decrease of exposure levels from 2013 to 2016 was evident, but much less pronounced than the increase between 2011 and 2013, meaning that the exposure levels in 2016 were considerably worse than in 2011.

\section{Discussion}

Three MIS studies have taken place in Madagascar since 2011, providing a valuable source of information about the status of malaria from a standardised data collection protocol applied across a nationally representative set of locations. A broad range of indicator metrics are included in the MIS reports. This present study looks at the parasitology data in particular to assess how the prevalence of malaria infection in children 6 to 59 months old has changed in recent years. Given the limitations of the routine health data reporting chain discussed previously [4], this study provides a complementary perspective into the recent status of malaria endemicity in Madagascar, identifying important increasing trends since 2011 despite a relatively small fall in prevalence between 2013 and 2016.

\section{Comparison with reported MIS results}

The results presented in MIS reports are summaries of the raw survey data, with individuals weighted in such a way as to ensure appropriate national representation in the overall summary statistics. However, the results are not adjusted for the temporal lag in survey dates across years (Additional file 1: Figure S1). By 2016, the survey time window was pushed to 2 months later than in 2011, corresponding to a delay away from the peak transmission period in most regions (Additional file 3: Figure S3 and Additional file 4: Figure S4). The model presented here specifically accounts for this temporal lag, allowing for meaningful comparisons between years. Seasonal trends in transmission [4] mean that a delayed survey period will underestimate endemicity relative to the original survey time period. This is reflected in the raw MIS results, which suggest a $6.2 \%$ national PfPR $\mathrm{P}_{6-59 \mathrm{mo}}$ in 2011 and 7\% in 2016, a 13\% 
increase over that period. In contrast, the spatiotemporal model presented here identifies a $127 \%$ increase, resulting in an estimated national mean $9.3 \%$ annual PfPR $_{6-59 m o}$ in 2016.

The MIS specifically excludes three highland districts considered to be malaria-free (the cities of AntananarivoRenivohitra, Antsirabe I and Fianarantsoa I) as well as communes above $1500 \mathrm{~m}$ in altitude. Despite not being represented in the mapping input dataset, model predictions are derived for these areas, which then inform the ecozone- and national-level summaries. Without prior exclusion of these zones, the model-based approach risked over-inflating the estimates of endemicity. Environmental covariates, however, appear to have discerned the unsuitability of the highland urban habitat, and the malaria-free districts are predicted to have $<0.5 \%$ infection prevalence in all 3 years. The overall ecozone-level mean annual PfPR $_{6-59 m o}$ for the central highlands was $0.6 \%$ in $2011,2.0 \%$ in 2013 and $1.6 \%$ in 2016 , which were of the same order of magnitude as those in the MIS summaries of $0.8 \%, 1.1 \%$ and $0.9 \%$, respectively. The excluded MIS sampling zones do not, therefore, seem to have impacted the spatio-temporal model predictions.

\section{Comparison with previous prevalence maps}

While geostatistical methods have been previously applied to infection prevalence datasets to predict spatially continuous prevalence maps of Madagascar, this has been within the context of continental or global-level mapping $[37,39]$. The country-specific modelling approach applied here allows more freedom to the environmental covariates to adapt to Madagascar's specific ecological context, with the model selecting those covariates most pertinent to the island's environmental diversity. The continentlevel spatio-temporal prediction cube developed by Bhatt et al. ([39], reproduced for Madagascar [4]), indicates a much coarser granularity than the present predictions, with little variation between years. Nevertheless, the continental maps do allow malaria endemicity in Madagascar to be viewed in its broader context, showing the relatively low prevalence of infection in Madagascar relative to many countries in sub-Saharan Africa (incidence rate ranked 13th lowest out of 43 countries in 2015 [39]). Prevalence mapping analyses are also valuable in evaluating trends in malaria prevalence over time.

\section{Comparison with health metrics information system data}

In this study, we map the parasite reservoir, as detectable by microscopy. In parallel, clinical case numbers are collated by the routine health metrics information system [4, 40, 41]. While the two metrics report different characteristics of malaria, spatio-temporal trends from both are similar, with a comparable geographic distribution of the burden of disease and an important increase in burden particularly along the west coast. A major increase in clinical cases was reported between 2014 and 2015, which subsequently reduced in 2016 (the third MIS year) following a mass distribution of bed nets treated with insecticide at the end of 2015 [41]. The longitudinal nature of the data from the health metrics information system allows extreme events to be identified, such as epidemics, which may drastically affect the annual case totals, as in 2015, but which may not be distinguishable as exceptional, or even captured by cross-sectional surveys that assess prevalence at isolated time points.

A 2017 World Health Organization (WHO) report estimates that only around $31 \%$ of all clinical cases are reported through the surveillance system to the central level in Madagascar. This is likely primarily driven by the population's low rates of seeking treatment. Of mothers seeking treatment in 2016 for their febrile children aged 6 to 59 months, $35.8 \%$ did so at public health facilities and $46.2 \%$ did so at any source (including public health facilities) [11]. Such low capture of the overall case burden, therefore, throws into question the system's capacity to adequately quantify changes in the malaria burden over time.

The two indicators, therefore, have their strengths and limitations, but together corroborate general trends of an increased burden between 2011 and 2016, punctuated with reductions, such as those identified between the 2013 and 2016 MIS surveys, or between 2015 and 2016 by the routinely reported case data $[40,41]$. This temporal heterogeneity may be partly attributable to reductions in NMCP activities caused by Global Fund disbursement delays in 2014 [40]. In addition, recent evidence of the variable quality and durability of the insecticide-treated bed-net brands distributed across the country means that over their 3-year lifespans (mass distribution campaigns in Madagascar are triennial), protection from nets will be inconsistent [42]. MIS campaigns in Madagascar have all been timed to take place in the transmission season following mass bed-net distribution campaigns, which may, therefore, capture snapshots of prevalence at its lowest.

\section{Limitations to the approach}

In this study, we have used data on the prevalence of infection to assess the current spatio-temporal trends of malaria infection in Madagascar. This metric is independent of clinical symptoms, and instead quantifies the extent of the parasite reservoir across the population. The value of such a metric lies in its simplicity and standardised collection methods, and, in the context of the MIS, repeated national representation. A recent review by Cohen and colleagues [43], however, has argued for a multi-component mapping process that will adequately identify the underlying drivers of transmission, to enable 
NMCP to target control measures optimally. Elimination requires both the reduction of the parasite reservoir and the prevention of transmission. Prevalence data alone cannot fully characterise the local epidemiology without a parallel understanding of a site's historical context, the significance of imported cases, the impact of recent control efforts, entomological and host behavioural/genetic factors, and so on [43]. A practical interpretation of the prevalence map, therefore, requires insight into the underlying factors driving the observed infection rates. The map suite presented here is one component in understanding malaria in Madagascar, but ought to be interpreted in association with a broader set of malariometric data when used to determine control intervention policy. Malaria transmission is also highly dynamic both spatially and temporally, meaning that predicted maps based on single time-point snapshots of prevalence may simplify the true underlying situation. Maps such as those presented here provide insight into general trends, and the validation statistics presented in Additional file 2: Figure S2, Additional file 3: Figure S3 and Additional file 4: Figure S4 indicate the level of variability that might be expected around these predictions.

Malaria prevalence is strongly influenced by intervention coverage levels, including rates of insecticidetreated net (ITN) ownership [39] and treatment seeking $[13,14]$. Including these covariates in the modelling framework could help inform the model about the patterns of endemicity but this was not considered feasible in this present analysis. The coverage of indoor residual spraying and ITN use rates, for instance, have complex non-linear relationships with malaria prevalence. For example, indoor residual spraying in Madagascar is carefully targeted to the highest (as an emergency response to reduce mortality during outbreaks) and lowest (prevention of reintroduction and subsequent autochthonous transmission) endemicity districts only [8]. ITN coverage is strongly skewed to areas where malaria is endemic. The highland areas into which malaria is mainly imported are not covered by routine ITN distribution. The limited temporal window considered in this present study does not allow for the protective effect of high ITN coverage to be learnt by the model, and instead the coarse learnt association is that ITN coverage increases as prevalence increases. Treatment seeking was excluded for reasons of sample sizes. MIS data on treatment seeking from individual cluster locations are limited to mothers with infants who suffered from fever in the 2 weeks preceding the MIS interviews. Sample sizes at the cluster level are, therefore, very small, producing spurious results when analysed at the high resolution of the present analysis. Despite these barriers to including intervention covariates in the model, the suite of environmental and socio-demographic variables that were used allowed robust predictions of malaria prevalence, so this was not considered a major limitation to the mapping model presented here.

Madagascar is noted for its mosaic landscape of ecological habitats, with land cover varying across short distances [44]. The critical importance of the environmental covariates in the modelling process is evident from the methods described here, with a strong predictive role associated with vegetation cover that explains differences in malaria prevalence between different areas (Table 2). The covariates associated with each MIS site describe the local conditions associated with the observed malaria prevalence at the time and location of sampling. However, MIS datasets are geopositioned with a deliberate degree of spatial uncertainty (displacement) to promote anonymity of up to $2 \mathrm{~km}$ in urban areas, $5 \mathrm{~km}$ in rural areas and $10 \mathrm{~km}$ for $1 \%$ of rural points [45]. This spatial displacement, therefore, introduces uncertainty into the associations between reported PfPR and their attributed covariate values, which could impact the model's predictions. For this study, we assumed that while the island is ecologically heterogeneous, the impact of this spatial uncertainty will be acceptably low (with ecological conditions similar for most points even at a distance of $5 \mathrm{~km}$ or $10 \mathrm{~km}$ ), and similar enough to allow a prevalence signal to be identified. The model validation statistics corroborate this assumption.

A further limitation of the MIS datasets that informed the current mapping analysis stems from their sampling design and sample sizes. The broad range of indicators included in the MIS activities present conflicting demands on sample sizes, which are further constrained by financial and logistical considerations. Sample sizes cannot, therefore, be optimised for all indicators, but instead are focussed on a limited number of these. A recent retrospective model-based analysis of the 2011 and 2013 Madagascar MIS datasets estimated that sample sizes were under-powered by $17 \%$ and $36 \%$, respectively, to reach effective sizes for infection prevalence rates [46]. This was based on rapid diagnostic test results and not microscopy (as considered in this present study), meaning that it may be a slight overestimate. The approach followed here, namely to consider samples from the three MIS datasets within a common Bayesian hierarchical modelling framework and to draw on a broad range of associated covariate surfaces, provides a solution to sample size limitations.

Furthermore, at very low transmission levels, such as in the central highlands and parts of the central fringe regions of Madagascar, microscopy-based cross-sectional surveys of parasite prevalence risk are underpowered to detect rare and low parasitaemia infections adequately [47]. In these areas, higher sensitivity diagnostics (such as nucleic-acid amplification-based approaches) and alternative indicators (such as serological markers) are 
required to monitor malaria epidemiological trends more effectively [47-50]. Particular interest is in the use of serological panels targeting both short- and longlasting antigenic responses [51]. When applied to appropriate sentinel populations $[52,53]$, these tools can be powerful probes of changing transmission intensity or reintroduction events in the pre-elimination setting where the majority of infections at the time of survey may be microscopically sub-patent [54].

\section{Conclusions}

Malaria remains an important health problem in Madagascar, with the prevalence of infection more than doubling between 2011 and 2016 (a mean increase of 127\%). Across the three survey time points, 2011 to 2013 saw the greatest $P f \mathrm{PR}_{6-59 \mathrm{mo}}$ increase, followed by a reduction to 2016 (mean reduction of $23 \%$ ). However, while the whole population is at risk of infection, prevalence was lower in higher density areas, with $26.7 \%$ of the population in 2016 living in pre-elimination areas, where prevalence was $<1 \%$ (a notable reduction from $42.3 \%$ of the population in 2011, however).

Presidential elections in December 2013 marked an optimistic turning point for Madagascar, with the return to democracy ending the country's 5-year isolation from the international community. The 2009-2013 political crisis placed a heavy burden on the country's socioeconomic situation, with a deterioration in infrastructure and public services [55]. The sharp increase in malaria prevalence observed from 2011 to 2013 is likely a consequence of the country's wider economic situation and associated health infrastructure breakdown.

Madagascar is not alone in suffering losses with malaria control, with most countries in the African WHO region also experiencing stalling progress [40]. Madagascar's new strategic plan for 2018-2022, however, offers an opportunity to strengthen control with a policy shift away from blanket coverage of intervention commodities, towards a more locally targeted programme responsive to specific epidemiological contexts [56]. The current government's strong support for malaria elimination is reflected by a move towards closer integration of the NMCP into the Ministry of Health's core structures and activities rather than being a quasi-independent programme, coupled with the objective of partially devolving responsibilities for control planning to regional officers. New policies include the reintroduction of entomological control interventions, targeted seasonal chemoprophylaxis in epidemic-prone south-western communities, expanding household insecticide residual spraying to the highest and lowest risk areas, and specific consideration of high-risk populations [8].

Ambitious targets are being set for the end of the next National Strategic Plan in 2022, with a view towards geographically progressive elimination. Prevalence maps, as presented here, represent one component of monitoring progress towards those goals.

\section{Additional files}

Additional file 1: Figure S1. Sample screening during the three MIS events in Madagascar, showing the progressive delay in the sampling time window. a Overall bar plots of sampling months. b-d Maps by sampling month by cluster location. (PNG 1353 kb)

Additional file 2: Figure S2. Month-specific correlations between observed raw MIS prevalence values and the model predictions for each annual map. Pearson correlation coefficients are shown on each plot. (PNG $32 \mathrm{~kb}$ )

Additional file 3: Figure S3. Box plots of a cross-validated Pearson correlation coefficients and b cross-validated $R^{2}$, based on 100 randomly sampled validation sets. (PNG $26 \mathrm{~kb}$ )

Additional file 4: Figure S4. Observed prevalence against predicted prevalence averaged across 100 randomly sampled validation sets. (PNG 63 kb)

Additional file 5: Figure S5. Summary box plots of predicted monthly PfPR $_{6-59 m o}$ by ecozone, plotted alongside temporally variable predictor values. The box plot rectangles indicate the first to third quartiles (interquartile range), with the median shown as the dark line inside the box. Vertical lines correspond to the minimum and maximum values. Specified lags indicate the time points that were selected by the model as explanatory variables of $P f R_{6-59 m o}$. A time lag of 0 indicates that the covariate values in the concurrent month were predictive of PfPR $6-59$ mor while a time lag of 3 indicates that the covariate value 3 months prior to the prediction was predictive of PfPR $6-59 \mathrm{mo}$. (ZIP $1859 \mathrm{~kb}$ )

Additional file 6: Figure S6. Predicted monthly mean PfPR $_{6-59 m o}$ maps for a 2011, c 2013 and e 2016, with associated uncertainty (interquartile range) for b 2011, d 2013 and f 2016. (ZIP $48310 \mathrm{~kb}$ )

Additional file 7: Figure S7. Maps of the coefficient of variation in the annual mean maps (standard deviation/annual mean) showing the relative confidence in the predictions across the country for a 2011, b 2013 and c 2016. (PNG 535 kb)

\section{Abbreviations}

AR1: First-order autoregressive prior distribution; CHIRPS: Climate Hazards Group Infrared Precipitation with Station Data; Cl: Credible interval; DHS: Demographic and Health Surveys; EVI: Enhanced vegetation index; GIS: Geographic information system; IQR: Interquartile range; ITN: Insecticidetreated net; LST: Land surface temperature; MAP: Malaria Atlas Project; MIS: Malaria Indicator Survey; MODIS: Moderate Resolution Imaging Spectroradiometer; NMCP: National Malaria Control Programme; NOAA: National Oceanic and Atmospheric Administration; OR: Odds ratio; P.: Plasmodium; SRTM: Shuttle Radar Topography Mission; TCB: Tasselled cap brightness; TCW: Tasselled cap wetness; VIF: Variance inflation factor; WHO: World Health Organization; WWF: World Wildlife Fund

\section{Acknowledgments}

The authors thank the two reviewers for their helpful feedback and suggestions for improvements to the manuscript.

\section{Funding}

SYK receives support from the Bill and Melinda Gates Foundation (OPP1159934). KEB, HSG, DJW and EC are funded through Bill and Melinda Gates Foundation grants to PWG (OPP1 106023 and OPP1152978). SR, AR, PAZ and REH are funded from a National Institutes of Health grant to PAZ (R01 Al097366). The funding bodies had no role in the study design, analysis, interpretation or decision to publish this manuscript.

\section{Availability of data and materials}

The datasets analysed during the current study are freely available from the DHS online data repository: https://dhsprogram.com/. 


\section{Authors' contributions}

REH, SYK, KEB, and PWG conceived the study. KEB and HG prepared the input data and covariate surfaces. SYK developed the statistical model. DW, EC and PWG advised on the analysis. AR and MR were involved with the original MIS activities and generation of parasite prevalence data. REH wrote the first draft of the manuscript with SYK and KEB. All authors contributed to the interpretation of results. All authors read and approved the final manuscript.

\section{Ethics approval and consent to participate}

Not applicable.

\section{Competing interests}

The authors declare that they have no competing interests.

\section{Publisher's Note}

Springer Nature remains neutral with regard to jurisdictional claims in published maps and institutional affiliations.

\section{Author details}

${ }^{1}$ Malaria Atlas Project, Oxford Big Data Institute, Nuffield Department of Medicine, University of Oxford, Oxford, UK. ${ }^{2}$ National Malaria Control Programme, Ministry of Health, Antananarivo, Madagascar. ${ }^{3}$ University of Antananarivo, Antananarivo, Madagascar. ${ }^{4}$ Institut Pasteur de Madagascar, Antananarivo, Madagascar. ${ }^{5}$ Faculté des Sciences, Université de Toliara, Toliara, Madagascar. ${ }^{6}$ Center for Global Health and Diseases, Case Western Reserve University, Cleveland, OH, USA

Received: 12 February 2018 Accepted: 24 April 2018

Published online: 23 May 2018

\section{References}

1. Joncour G. The fight against malaria in Madagascar. Bull World Health Organ. 1956;15:711-23.

2. Mouchet J, Blanchy S. Particularités et stratification du paludisme à Madagascar. Santé. 1995;5:386-8.

3. Randrianarivelojosia M, Raveloson A, Randriamanantena A, Juliano J, Andrianjafy $T$, Raharimalala LA, et al. Lessons learnt from the six decades of chloroquine use (1945-2005) to control malaria in Madagascar. Trans R Soc Trop Med Hyg. 2009;103:3-10.

4. Howes RE, Mioramalala SA, Ramiranirina B, Franchard T, Rakotorahalahy AJ, Bisanzio D, et al. Contemporary epidemiological overview of malaria in Madagascar: operational utility of reported routine case data for malaria control planning. Malar J. 2016:15:502

5. Albonico M, De Giorgi F, Razanakolona J, Raveloson A, Sabatinelli G, Pietra V et al. Control of epidemic malaria on the highlands of Madagascar. Parassitologia. 1999;41:373-6.

6. Laventure S, Mouchet J, Blanchy S, Marrama L, Rabarison P Andrianaivolambo $L$, et al. Rice: source of life and death on the plateaux of Madagascar. Sante. 1996;6:79-86.

7. Girond F, Randrianasolo L, Randriamampionona L, Rakotomanana F, Randrianarivelojosia M, Ratsitorahina M, et al. Analysing trends and forecasting malaria epidemics in Madagascar using a sentinel surveillance network: a web-based application. Malar J. 2017;16:72.

8. National Malaria Control Programme of Madagascar. National strategic plan for malaria control in Madagascar 2018-2022. Progressive malaria elimination from Madagascar. (2017).

9. Institut National de la Statistique (INSTAT), Programme National de Lutte contre le Paludisme (PNLP), and ICF International. Madagascar Malaria Indicator Survey 2011 [Enquête sur les Indicateurs du Paludisme (EIPM)]. Calverton: INSTAT, PNLP, and ICF International; 2011.

10. Institut National de la Statistique (INSTAT), Programme National de Lutte contre le Paludisme (PNLP), Institut Pasteur de Madagascar (IPM), and ICF International. Madagascar Malaria Indicator Survey 2013 [Enquête sur les Indicateurs du Paludisme (EIPM)]. Calverton: INSTAT, PNLP, IPM and ICF International; 2013.

11. Institut National de la Statistique (INSTAT), Programme National de Lutte contre le Paludisme (PNLP), Institut Pasteur de Madagascar (IPM), and ICF International. Madagascar Malaria Indicator Survey 2016 [Enquête sur les Indicateurs du Paludisme (EIPM)]. Calverton: INSTAT, PNLP, IPM and ICF International; 2016
12. Barmania S. Madagascar's health challenges. Lancet. 2015;386:729-30.

13. Cibulskis RE, Aregawi M, Williams R, Otten M, Dye C. Worldwide incidence of malaria in 2009: estimates, time trends, and a critique of methods. PLoS Med. 2011:8:e1001142.

14. Battle KE, Bisanzio D, Gibson HS, Bhatt S, Cameron E, Weiss DJ, et al. Treatment-seeking rates in malaria endemic countries. Malar J. 2016:15:20.

15. Weiss DJ, Mappin B, Dalrymple U, Bhatt S, Cameron E, Hay SI, et al. Reexamining environmental correlates of Plasmodium falciparum malaria endemicity: a data-intensive variable selection approach. Malar J. 2015;14:68.

16. National Oceanic and Atmospheric Administration (NOAA) National Centers for Environmental Information. Defense Meteorological Satellite Program (DMSP): Data Archive, Research, and Products. http://ngdc.noaa.gov/eog/ dmsp.html. Accessed Sept 2017.

17. Noor AM, Alegana VA, Gething PW, Tatem AJ, Snow RW. Using remotely sensed night-time light as a proxy for poverty in Africa. Popul Health Metrics. 2008;6:5.

18. Nelson A. Travel time to major cities: A global map of Accessibility. Ispra: Global Environmental Monitoring Unit - Joint Research Centre of the European Commission; 2008. http://forobs.jrc.ec.europa.eu/products/gam/. Accessed Sept 2017

19. Farr TG, Rosen PA, Caro E, Crippen R, Duren R, Hensley S, et al. The Shuttle Radar Topography Mission. Rev Geophys. 2007;45:RG2004.

20. ESRI. ArcGIS Desktop 10.5.1. Redlands: Environmental Systems Resource Institute; 2017.

21. HydroSHEDS database. http://hydrosheds.org/. Accessed Sept 2017

22. World Wildlife Fund (WWF). Global Lakes and Wetlands Database. Washington, DC; 2004. https://www.worldwildlife.org/pages/global-lakesand-wetlands-database. Accessed Sept 2017.

23. Trabucco A, Zomer RJ. Global aridity index (global-aridity) and global potential evapo-transpiration (global-PET) geospatial database. CGIAR Consortium for Spatial Information ed. 2009. Available online from the CGIAR-CSI GeoPortal at: http://www.cgiar-csi.org/. Accessed Sept 2017.

24. Linard C, Gilbert M, Snow RW, Noor AM, Tatem AJ. Population distribution, settlement patterns and accessibility across Africa in 2010 PLoS One. 2012;7:e31743.

25. Funk CC, Peterson PJ, Landsfeld MF, Pedreros DH, Verdin JP, Rowland $J D$, et al. A quasi-global precipitation time series for drought monitoring: U.S. Geological Survey Data Series, vol. 832; 2014. https:// doi.org/10.3133/ds832.

26. Weiss DJ, Bhatt S, Mappin B, Van Boeckel TP, Smith DL, Hay SI, et al. Air temperature suitability for Plasmodium falciparum malaria transmission in Africa 2000-2012: a high-resolution spatiotemporal prediction. Malar J. 2014;13:171.

27. Gething PW, Van Boeckel TP, Smith DL, Guerra CA, Patil AP, Snow RW, et al. Modelling the global constraints of temperature on transmission of Plasmodium falciparum and P. vivax. Parasit Vectors. 2011;4:92.

28. NASA. Moderate Resolution Imaging Spectroradiometer (MODIS). https:// modis.gsfc.nasa.gov/. Accessed Sept 2017

29. Weiss DJ, Atkinson PM, Bhatt S, Mappin B, Hay SI, Gething PW. An effective approach for gap-filling continental scale remotely sensed time-series. ISPRS J Photogramm Remote Sens. 2014:98:106-18.

30. NASA Earth Observations (NEO). Average land surface temperature. http:// neo.sci.gsfc.nasa.gov/view.php?datasetld=MOD_LSTD_CLIM_M. Accessed Sept 2017.

31. NASA Earth Data. MODIS (MOD 13) - Gridded Vegetation Indices (NDVI and EVI). http://modis.gsfc.nasa.gov/data/dataprod/dataproducts.php?MOD_ NUMBER=13. Accessed Sept 2017.

32. NASA Earth Data. Land Processes Distributed Active Archive Center. https:// Ipdaac.usgs.gov/dataset_discovery/modis/modis_products_table/mcd43b5. Accessed Sept 2017

33. Rue H, Martino S, Chopin N. Approximate Bayesian inference for latent Gaussian models by using integrated nested Laplace approximations. J Royal Stat Soc Series B Stat Methodo. 2009;71:319-92.

34. Cameletti M, Lindgren F, Simpson D, Rue H. Spatio-temporal modeling of particulate matter concentration through the SPDE approach. Adv Stat Ana. 2013;97:109-31.

35. Clayton D, Kaldor J. Empirical Bayes Estimates of Age-Standardized Relative Risks for Use in Disease Mapping. Biometrics. 1987:43:671-81.

36. Waller L, Carlin B. Disease mapping. In: Gelfand AE, Diggle P, Guttorp P, Fuentes $M$, editors. Handbook of Spatial Statistics. Boca-Raton: CRC Press; 2010 
37. Gething PW, Patil AP, Smith DL, Guerra CA, Elyazar IR, Johnston GL, et al. A new world malaria map: Plasmodium falciparum endemicity in 2010. Malar J. 2011;10:378

38. Rice BL, Golden CD, Anjaranirina EJ, Botelho CM, Volkman SK, Hartl DL. Genetic evidence that the Makira region in northeastern Madagascar is a hotspot of malaria transmission. Malar J. 2016;15:596.

39. Bhatt S, Weiss DJ, Cameron E, Bisanzio D, Mappin B, Dalrymple U, et al. The effect of malaria control on Plasmodium falciparum in Africa between 2000 and 2015. Nature. 2015;526:207-11.

40. WHO. World Malaria Report 2017. Geneva: World Health Organization; 2017.

41. National Malaria Control Programme of Madagascar. Malaria Programme Review 2017 [Revue du Programme National de Lutte contre le Paludisme]. Antananarivo: Ministry of Health of Madagascar; 2017.

42. Randriamaherijaona S, Raharinjatovo J, Boyer S. Durability monitoring of long-lasting insecticidal (mosquito) nets (LLINs) in Madagascar: physical integrity and insecticidal activity. Parasit Vectors. 2017;10:564.

43. Cohen JM, Le Menach A, Pothin E, Eisele TP, Gething PW, Eckhoff PA, et al. Mapping multiple components of malaria risk for improved targeting of elimination interventions. Malar J. 2017;16:459.

44. Virah-Sawmy M, Gillson L, Willis KJ. How does spatial heterogeneity influence resilience to climatic changes? Ecological dynamics in southeast Madagascar. Ecol Monogr. 2009;79:557-74.

45. Burgert CR, Colston J, Roy T, Zachary B. Geographic displacement procedure and georeferenced data release policy for the demographic and health surveys. In: DHS Spatial Analysis Reports No 7. Calverton: ICF International; 2013. https://dhsprogram.com/pubs/pdf/SAR7/SAR7.pdf.

46. Alegana VA, Wright J, Bosco C, Okiro EA, Atkinson PM, Snow RW, et al. Malaria prevalence metrics in low- and middle-income countries: an assessment of precision in nationally-representative surveys. Malar J. 2017;16:475.

47. Dalrymple U, Mappin B, Gething PW. Malaria mapping: understanding the global endemicity of falciparum and vivax malaria. BMC Med. 2015;13:140.

48. Yalew WG, Pal S, Bansil P, Dabbs R, Tetteh K, Guinovart C, et al. Current and cumulative malaria infections in a setting embarking on elimination: Amhara, Ethiopia. Malar J. 2017;16:242.

49. Corran P, Coleman P, Riley E, Drakeley C. Serology: a robust indicator of malaria transmission intensity? Trends Parasitol. 2007;23:575-82.

50. Zimmerman PA, Howes RE. Malaria diagnosis for malaria elimination. Curr Opin Infect Dis. 2015;28:446-54.

51. Helb DA, Tetteh KK, Felgner PL, Skinner J, Hubbard A, Arinaitwe E, et al. Novel serologic biomarkers provide accurate estimates of recent Plasmodium falciparum exposure for individuals and communities. Proc Natl Acad Sci U S A. 2015;112:E4438-47.

52. Ray K, Upreti HB, Yadav RN, Sharma MC, Mukherjee AK, Sharma GK. Evaluation of serology as a tool for malaria surveillance in East Champaran District of Bihar, India. Ann Trop Med Parasitol. 1988;82:225-8.

53. Elliott SR, Fowkes FJ, Richards JS, Reiling L, Drew DR, Beeson JG. Research priorities for the development and implementation of serological tools for malaria surveillance. F1000Prime Rep. 2014:6:100.

54. Stresman GH, Stevenson JC, Ngwu N, Marube E, Owaga C, Drakeley C, et al. High levels of asymptomatic and subpatent Plasmodium falciparum parasite carriage at health facilities in an area of heterogeneous malaria transmission intensity in the Kenyan highlands. Am J Trop Med Hyg. 2014;91:1101-8.

55. The World Bank. Madagascar: Measuring the Impact of the Political Crisis. Washington DC; 2013. http://www.worldbank.org/en/news/feature/2013/06/ 05/madagascar-measuring-the-impact-of-the-political-crisis. Accessed 31 Jan 2016.

56. Baird JK. Malaria control by commodities without practical malariology. BMC Public Health. 2017;17:590.

\section{Ready to submit your research? Choose BMC and benefit from:}

- fast, convenient online submission

- thorough peer review by experienced researchers in your field

- rapid publication on acceptance

- support for research data, including large and complex data types

- gold Open Access which fosters wider collaboration and increased citations

- maximum visibility for your research: over $100 \mathrm{M}$ website views per year

At BMC, research is always in progress.

Learn more biomedcentral.com/submissions 